\title{
Thyroid Transcription Factor-1 in Normal, Hyperplastic, and Neoplastic Follicular Thyroid Cells Examined by Immunohistochemistry and Nonradioactive In Situ Hybridization
}

Ryohei Katoh, M.D., Ph.D., Akira Kawaoi, M.D., Ph.D., Eri Miyagi, Ph.D., Xin Li, M.D., Koichi Suzuki, Ph.D., Yasushi Nakamura, M.D., Ph.D., Kenichi Kakudo, M.D., Ph.D.

Department of Pathology, Yamanashi Medical University School of Medicine (RK, AK, EM, XL), Tamaho, Japan; Cell Regulation Section, Metabolic Diseases Branch, National Institute of Diabetes and Digestive and Kidney Diseases, National Institutes of Health (KS), Bethesda, Maryland; and Department of Pathology, Wakayama Medical College (YN, KK), Wakayama, Japan

Thyroid transcription factor-1 (TTF-1) has been known to regulate the transcriptional activity of thyroid-specific genes. We examined the expression of TTF-1 in non-neoplastic and neoplastic thyroid tissues. By immunohistochemistry, the nuclei of normal and hyperplastic follicular cells strongly reacted with the antibody against TTF-1. Immunohistochemistry also revealed a distinctive nuclear positivity of TTF- 1 in all 33 differentiated follicular cell tumors, including 15 follicular adenomas, 5 follicular carcinomas, and 13 papillary carcinomas. No immunoreactions were observed in three of four undifferentiated carcinomas, whereas an isolated and weak nuclear positivity was obtained in one. In normal and hyperplastic tissues, the distribution of TTF- 1 was fairly related to that of thyroid-specific proteins thyroglobulin and thyroperoxidase. However, discrepancies in the distribution were observed in tumor tissues. By in situ hybridization, the riboprobe hybridized distinctively with the cytoplasm of neoplastic cells as well as normal follicular cells. Papillary carcinoma cells expressed TTF-1 mRNA in all but two cases, and its expression was also demonstrated in one of four undifferentiated carcinomas. Reverse transcription-polymerase chain reaction confirmed the presence of TTF-1 mRNA in two human undifferentiated carcinoma cell lines, TTA-1 and TTA-2. In conclusion, the investigation of TTF-1 provides useful information on the functional activities and/or differentiation of

Copyright () 2000 by The United States and Canadian Academy of Pathology, Inc.

VOL. 13, NO. 5, P. 570, 2000 Printed in the U.S.A.

Date of acceptance: November 12, 1999.

Address reprint requests to: Ryohei Katoh, M.D., Ph.D., Department of Pathology, Yamanashi Medical University School of Medicine, 1110 Shimokato, Tamaho-cho, Nakakoma-gun, Yamanashi 409-38, Japan; e-mail: rkatoh@res.yamanashi-med.ac.jp; fax: 81-552-73-9534. thyroid tumors and may lead to an increase in our understanding of the biologic nature of thyroid tumors.

KEY WORDS: Immunohistochemistry, In situ hybridization, Reverse transcription-polymerase chain reaction, Thyroid neoplasms, Thyroid transcription factor-1.

Mod Pathol 2000;13(5):570-576

The thyroid-differentiated phenotype is characterized by the expression of a variety of proteins that are specifically synthesized by the thyroid follicular cells. Four genes encoding thyroid-specific proteins have been cloned: thyroglobulin (Tg), thyroperoxidase (TPO), thyroid-stimulating hormone receptor (1), and, more recently, thyroid iodine transporter (2). This tissue-restricted protein production is regulated, at least in part, by the thyroid-specific nuclear factors, thyroid transcription factors 1 and 2 (TTF-1 and TTF-2) $(3,4)$ and Pax-8 (5). All of them bind to Tg and TPO promoters $(5,6)$. TTF- 1 and Pax-8, however, preferentially bind to the $\mathrm{Tg}$ and TPO promoters, respectively (5). In addition, TTF-1 binds to the thyroid-stimulating hormone receptor gene promoter $(7,8)$. An important feature of TTF-1 is that it is a homeoprotein (4). This kind of protein plays very important roles in development, cell growth, and differentiation processes (9). Other than thyrocytes, TTF-1 is expressed in some regions of the central nervous system and in the lung, where it regulates the activity of tissue-specific genes not related to the thyroid (10-12).

The role of TTF-1 as a critical transcription factor regulating the gene expression of thyroid-specific proteins has been well documented in cell culture systems, particularly the FRTL-5 cell line $(1-4,6$, 13-15). However, little is known about the localiza- 
tion or distribution of TTF-1 protein and mRNA in human thyroid tumor tissues (16). Especially, there has been no investigation on the in situ expression of TTF-1 mRNA and its correlation with the presence of thyroid-specific proteins in human thyroid tissue specimens. Therefore, we investigated the expression and localization of TTF-1 in normal, hyperplastic, and neoplastic human thyroid tissues using immunohistochemistry (IHC) and nonisotopic in situ hybridization (ISH). Furthermore, we sought to determine whether TTF-1 expression profiles are of any value for estimating the biologic nature of thyroid neoplasms.

\section{MATERIALS AND METHODS}

\section{Tissue Preparation}

We reviewed the surgically resected specimens of various histologic types of thyroid tumors from the files of the Department of Pathology at Yamanashi Medical University and Kofu City Hospital and selected 47 cases for immunohistochemical and ISH studies. The materials consisted of tissues from 5 cases of normal thyroid, 5 multinodular goiters, 15 follicular adenomas, 5 follicular carcinomas, 13 papillary carcinomas, and 4 undifferentiated carcinomas. The criteria for selection included representative morphologic characteristics and adequate tissue mass. In tumor cases, the lesions were classified according to the diagnostic criteria of the World Health Organization classification proposed in 1988. All specimens were routinely processed, and paraffin blocks were available in all cases.

\section{Immunohistochemistry}

For immunohistochemical analysis, the following antibodies were used: mouse anti-TTF-1 monoclonal antibody (Neomarkers, Fremont, CA), rabbit antihuman thyroglobulin polyclonal antibody (originally produced) at a dilution of 1:500, and mouse antithyroid peroxidase monoclonal antibody (Canadian Bioclinical, Scarborough, Canada) at a dilution of 1:100. Antirabbit-IgG or antimouse IgG conjugates (DAKO, Glostrup, Denmark) were applied to the sections as a second antibody.

For TTF-1 staining, heat pretreatment of the paraffin sections was used for antigen retrieval. Sections were cut and mounted on poly-L-lysinecoated slides. Deparaffinized sections were placed first in plastic Coplin jars filled with citrate buffer (pH 6.0) and incubated for $10 \mathrm{~min}$ at $120^{\circ} \mathrm{C}$ in an autoclave. After autoclave pretreatment, the sections were allowed to cool to room temperature and were then exposed to a $0.3 \%$ solution of hydrogen peroxide in absolute methanol to inactivate endogenous peroxidase.
Indirect immunoperoxidase staining was used according to standard protocols (17). The sections were rinsed with phosphate-buffered saline (PBS), $\mathrm{pH} 7.2$, and incubated overnight at $4^{\circ} \mathrm{C}$ with primary antibody. Tissue sections were then washed, reacted with secondary antibody for $1 \mathrm{~h}$ at room temperature, washed, reacted with 3,3'-diaminobenzidine substrate, washed, and stained with methyl green or hematoxylin.

For serum controls, normal rabbit serum or PBS was used instead of the primary antibody. The tissues from liver and kidney were used as a negative control.

\section{In Situ Hybridization}

For riboprobe preparation, a 757 bp SacII fragment (149-905 bp) of TTF-1 cDNA was subcloned into Bluescript SK ${ }^{+}$(Stratagene; La Jolla, CA). TTF-1 cDNA was a kind gift from Dr. R. Di Lauro (Stazione Zoologica A. Dohrn, Villa Comunale, Naples, Italy). Antisense and sense riboprobes were transcribed in the presence of digoxigenin-11-uridine-5'-triphosphate (Boehringer Mannheim GmbH Biochemica, Mannheim, Germany) using T7 or T3 RNA polymerases, respectively.

The ISH protocol was a modification of a method described by Nomura et al. (18). In brief, sections were deparaffinized with xylene, rehydrated with a graded series of ethanol solutions, rinsed in PBS at $\mathrm{pH} 7.4$, postfixed with $4 \%$ paraformaldehyde for 5 min, rinsed in PBS, and digested with $20 \mu \mathrm{g} / \mathrm{mL}$ proteinase K (Sigma, St Louis, MO) at $37^{\circ} \mathrm{C}$ for 20 min. Slides were fixed again with $4 \%$ paraformaldehyde for $5 \mathrm{~min}$, rinsed with PBS, treated with an $0.02 \%$ glycine solution for 15 min, rinsed with PBS, dehydrated in graded solutions of ethanol, and air dried.

Probes were diluted with hybridization solution (10 mm Tris- $\mathrm{Cl} \mathrm{pH} \mathrm{7.6,} \mathrm{containing} 50 \%$ formamide, $200 \mu / \mathrm{mL}$ transfer RNA, $1 \times$ Denhardt's solution, $10 \%$ dextran sulfate, $600 \mathrm{~mm} \mathrm{NaCl}, 0.25 \%$ sodium dodecyl sulfate, and $1 \mathrm{~mm}$ EDTA) to a final concentration of $10 \mathrm{ng} / \mathrm{mL}$, and sections were hybridized with heat-denatured riboprobe for $18 \mathrm{~h}$ at $55^{\circ} \mathrm{C}$. After hybridization, samples were washed sequentially in $5 \times$ standard saline citrate (SSC) for $5 \mathrm{~min}$ at $55^{\circ} \mathrm{C}$, then $2 \times$ SSC containing $50 \%$ formamide for $30 \mathrm{~min}$ at $55^{\circ} \mathrm{C} ; 1 \times \mathrm{SSC}$ is composed of $0.15 \mathrm{M}$ $\mathrm{NaCl}$ and $0.015 \mathrm{~m}$ sodium citrate. To degrade unbound riboprobe, sections were treated with RNase A $(1 \mu \mathrm{g} / \mathrm{mL}$ in $10 \mathrm{~mm}$ Tris-Cl pH 7.6, $500 \mathrm{~mm} \mathrm{NaCl}$, $1 \mathrm{~mm}$ EDTA) at $37^{\circ} \mathrm{C}$ for $30 \mathrm{~min}$, then sequentially washed once in $2 \times \mathrm{SSC}$ for $20 \mathrm{~min}$ at $55^{\circ} \mathrm{C}$ and twice in $0.2 \times \mathrm{SSC}$ for $20 \mathrm{~min}$ at $55^{\circ} \mathrm{C}$. Hybridized probe was detected using a Nucleic Acid Detection Kit (Boehringer) according to the manufacturer's instructions. Briefly, slides were incubated with 
$1.5 \%$ blocking reagent for $30 \mathrm{~min}$ at room temperature, then incubated with a 1:500 dilution of alkaline phosphatase-labeled sheep antidigoxigenin Fab fragment for $1 \mathrm{~h}$ at room temperature. After washing, slides were incubated with substrate solution containing nitroblue tetrazolium salt and X-Phosphate (5-bromo-4-chloro-3-indoyl phosphate, toluidium salt) for 2 to $12 \mathrm{~h}$, counterstained with methyl green and mounted with a glyceringelatin solution.

\section{Reverse Transcription-Polymerase Chain Reaction}

Total RNAs were prepared by the acid guanidinium-phenol-chloroform system (ISOGEN,
Nippon Gene Co., Ltd., Toyama, Japan) as described in the manufacturer's instructions. Isolated total RNA $(20 \mu \mathrm{g})$ was fractionated by electrophoresis on $1.5 \%$ agarose in $18 \%$ formaldehyde gels. The quality of the extracted RNAs was checked by ethidium bromide staining; only RNAs showing two clear bands of $28 \mathrm{~S}$ and $18 \mathrm{~S}$, corresponding to ribosomal RNAs, were selected for further studies. Five micrograms of total RNA was reverse-transcribed using murine leukemia virus reverse transcriptase. PCRs were carried out according to the Gene Amp DNA amplification reagent kit instructions (PerkinElmer Cetus, Norwalk, CT), with modifications as described. Thirty cycles were performed. During each cycle, the samples were heated to $94^{\circ} \mathrm{C}$ for 30

TABLE 1. Summary of Immunohistochemistry (IHC) for TTF-1, Tg, and TPO and In Situ Hybridization (ISH) for TTF-1 mRNA

\begin{tabular}{|c|c|c|c|c|}
\hline \multirow{2}{*}{ Histologic type } & \multicolumn{3}{|c|}{ IHC } & \multirow{2}{*}{ ISH for TTF-1 mRNA } \\
\hline & TTF-1 & $\mathrm{Tg}$ & TPO & \\
\hline 1. normal thyroid & +++ & ++ & ++ & +++ \\
\hline 2. normal thyroid & +++ & + & ++ & +++ \\
\hline 3. normal thyroid & +++ & +++ & +++ & +++ \\
\hline 4. normal thyroid & +++ & ++ & +++ & +++ \\
\hline 5. normal thyroid & +++ & ++ & ++ & +++ \\
\hline 6. nodular goiter & +++ & ++ & +++ & +++ \\
\hline 7. nodular goiter & +++ & ++ & +++ & +++ \\
\hline 8. nodular goiter & +++ & ++ & +++ & +++ \\
\hline 9. nodular goiter & +++ & +++ & +++ & +++ \\
\hline 10. nodular goiter & +++ & +++ & +++ & +++ \\
\hline 11. follicular adenoma & +++ & ++ & +++ & ++ \\
\hline 12. follicular adenoma & +++ & + & ++ & ++ \\
\hline 13. follicular adenoma & ++ & + & ++ & +++ \\
\hline 14. follicular adenoma & +++ & ++ & +++ & ++ \\
\hline 15. follicular adenoma & ++ & + & ++ & + \\
\hline 16. follicular adenoma & +++ & ++ & ++ & +++ \\
\hline 17. follicular adenoma & +++ & ++ & ++ & ++ \\
\hline 18. follicular adenoma & ++ & ++ & ++ & + \\
\hline 19. follicular adenoma & +++ & + & +++ & +++ \\
\hline 20. follicular adenoma & +++ & ++ & +++ & +++ \\
\hline 21. follicular adenoma & +++ & + & ++ & ++ \\
\hline 22. follicular adenoma & ++ & ++ & ++ & ++ \\
\hline 23. follicular adenoma & ++ & ++ & ++ & +++ \\
\hline 24. follicular adenoma & +++ & + & ++ & ++ \\
\hline 25. follicular adenoma & +++ & ++ & + & ++ \\
\hline 26. follicular carcinoma & ++ & ++ & - & ++ \\
\hline 27. follicular carcinoma & ++ & ++ & + & ++ \\
\hline 28. follicular carcinoma & + & + & + & + \\
\hline 29. follicular carcinoma & ++ & ++ & ++ & +++ \\
\hline 30. follicular carcinoma & +++ & ++ & ++ & +++ \\
\hline 31. papillary carcinoma & +++ & ++ & + & +++ \\
\hline 32. papillary carcinoma & ++ & + & + & - \\
\hline 33. papillary carcinoma & +++ & ++ & + & ++ \\
\hline 34. papillary carcinoma & + & - & + & ++ \\
\hline 35. papillary carcinoma & ++ & + & + & +++ \\
\hline 36. papillary carcinoma & +++ & ++ & - & ++ \\
\hline 37. papillary carcinoma & ++ & ++ & + & + \\
\hline 38. papillary carcinoma & ++ & + & + & ++ \\
\hline 39. papillary carcinoma & ++ & ++ & - & - \\
\hline 40. papillary carcinoma & +++ & ++ & - & ++ \\
\hline 41. papillary carcinoma & +++ & + & - & +++ \\
\hline 42. papillary carcinoma & ++ & + & - & ++ \\
\hline 43. papillary carcinoma & +++ & ++ & - & +++ \\
\hline 44. undifferentiated carcinoma & + & - & - & + \\
\hline 45. undifferentiated carcinoma & - & - & - & - \\
\hline 46. undifferentiated carcinoma & - & - & - & - \\
\hline 47. undifferentiated carcinoma & - & - & - & - \\
\hline
\end{tabular}

TTF-1, thyroid transcription factor-1; Tg, thyroglobulin; TPO, thyroperoxidase; - , negative;,$+<10 \%$ tumor cells positive;,$++ 10-40 \%$ tumor cells positive;,$+++>50 \%$ tumor cells positive. 
seconds, cooled to $56^{\circ} \mathrm{C}$ for 60 seconds, and heated to $72^{\circ} \mathrm{C}$ for 60 seconds. The reverse transcription PCR (RT-PCR) reagent blank yielded no detectable products. A 16- $\mu$ l sample of each $50 \mu$ l PCR solution was fractionated by electrophoresis in a $2 \%$ agarose gel. Gels were photographed using Polaroid 655 film. The following oligonucleotide primers located at exon 1 and exon 2 of TTF-1 gene were used: TTF-1 5' oligonucleotide, CCAGGACACCATGAGGAACA; TTF-1 3' oligonucleotide, TGCACTCGTTCTTGTACCGG. RNAs extracted from stomach, colon, and liver were used as a negative tissue control.

\section{Cell Culture}

Two cell lines, TTA-1 and TTA-2, were used as models of human undifferentiated thyroid carci- noma (19). These two cell lines maintained the properties of the parent tumor. The medium was changed every other day, and cells were passaged every 6 to 8 days.

\section{RESULTS}

\section{Immunohistochemistry}

A summary of the IHC results is shown in Table 1. Immunoperoxidase staining with anti-TTF-1 antibody revealed that normal and hyperplastic thyroid tissues exhibited positive reaction products in the nuclei of most follicular cells as a fine granular pattern (Figs. 1A, B). The cell nuclei in kidney, colon, and stomach were nonreactive (data not shown). A strong nuclear positivity of TTF-1 protein
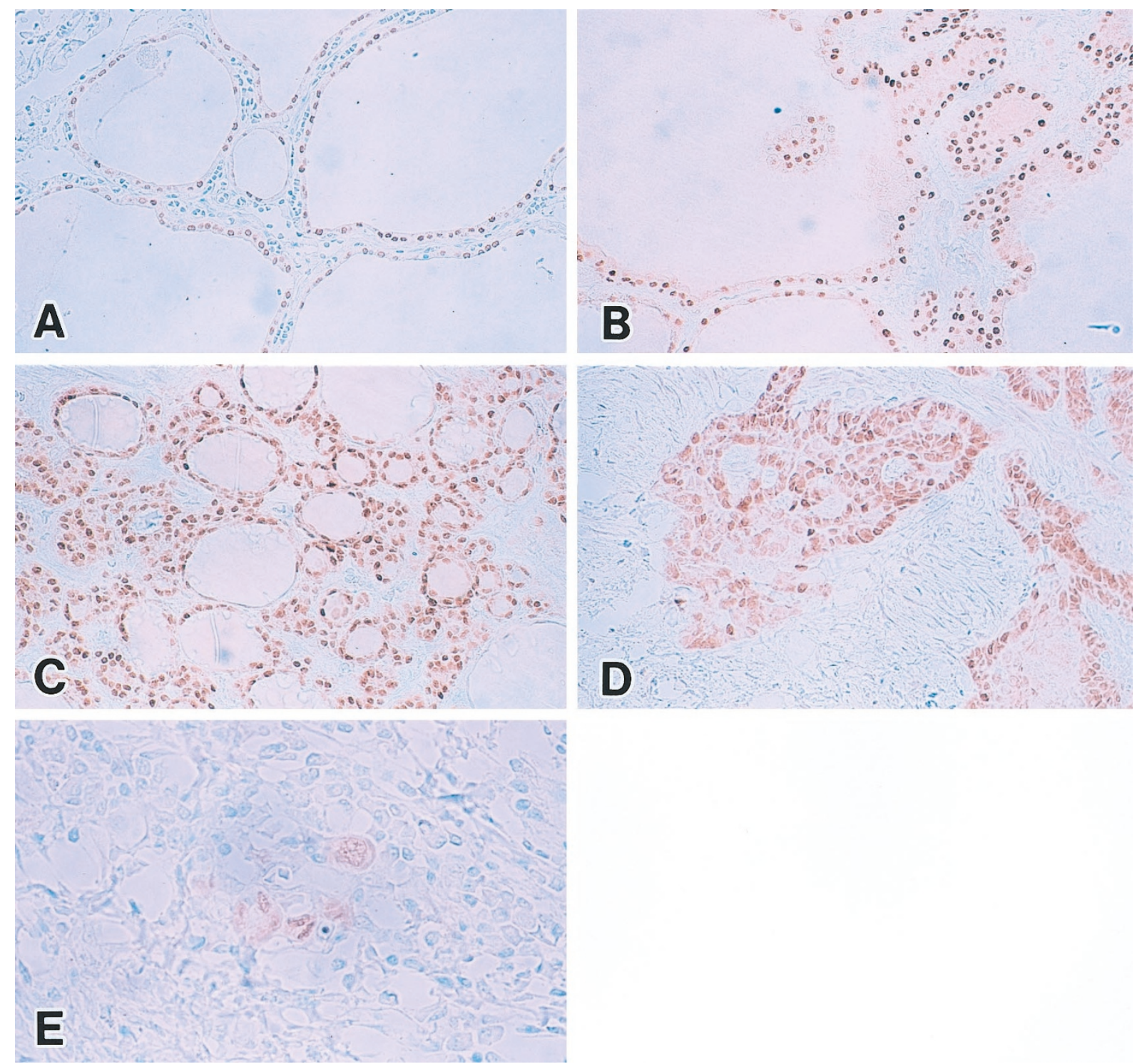

FIGURE 1. Immunohistochemical analysis of TTF-1 protein. The nuclei of almost all normal (A; magnification, $\times 200)$ and hyperplastic (B; magnification, $\times 200$ ) follicular cells strongly reacting with the antibody against TTF-1. C, follicular adenoma tissues showing positive reaction products in the nuclei of cells in a fine granular pattern (magnification, $\times 200$ ). D, positive reaction products are found in the nuclei of papillary carcinoma cells (magnification, $\times 200$ ). E, isolated cells of undifferentiated carcinoma are positive for TTF-1 (original magnification, $\times 400$ ). 
was also observed in all 33 differentiated follicular cell tumors, including 15 follicular adenomas, 5 follicular carcinomas, and 13 papillary carcinomas, whereas a weak and isolated positivity was demonstrated in one of four undifferentiated carcinomas (Figs. 1C-E). Immunostainings for thyroid-specific proteins Tg and TPO were performed on the serial sections for comparison with TTF-1 results (Table 1). Discrepancies in positive-cell distribution between TTF-1 and thyroid-specific proteins were observed in cancerous tissues (Table 1). All four undifferentiated carcinomas examined showed a lack of Tg and TPO proteins.

\section{In Situ Hybridization}

Specificity was established by comparing the ISH using the antisense and sense probes (data not shown). An antisense TTF-1 riboprobe but not a counterpart sense probe exhibited a positive signal for TTF-1 mRNA in the perinuclear region of the thyroid follicular epithelium. Expression levels of TTF-1 mRNA among follicles were not uniform in normal thyroid tissue (Fig. 2A). Slight expression of TTF-1 mRNA was detected in the flat thyroid epithelium lining the lumen of large follicles. In contrast, the cuboidal or columnar cells of small folli-
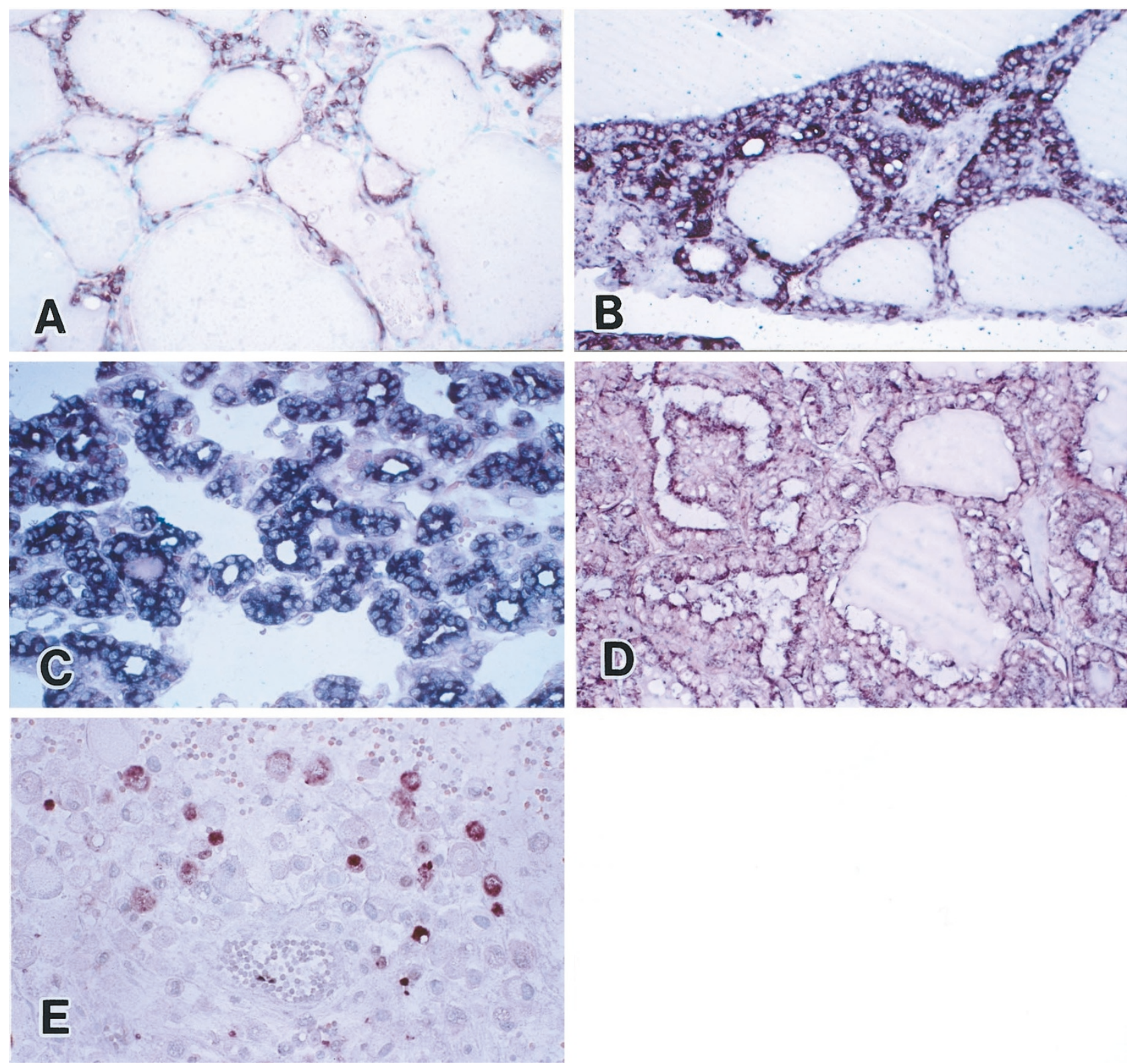

FIGURE 2. Findings of in situ hybridization of TTF-1 mRNA. A, in normal thyroid, little expression of TTF-1 mRNA is demonstrated in the flat thyroid epithelium lining the lumen of large follicles, whereas the cuboidal cells of small follicles show strong expression (magnification, $\times 200$ ). Multinodular goiter (B; magnification, $\times 40$ ), follicular adenoma (C; magnification, $\times 200)$, and papillary carcinoma $(\mathbf{D} ;$ magnification, $\times 200)$ showing diffuse expression of TTF-1 mRNA. E, distinctive expression of TTF-1 mRNA is observed in isolated tumor cells of undifferentiated carcinoma (magnification, $\times 400$ ). 
cles showed strong expression of TTF-1 mRNA (Fig. 2A). Hyperplastic thyroid tissues such as multinodular goiter (Fig. 2B) showed diffuse expression of TTF-1 mRNA in follicular cells. In follicular adenomas and follicular carcinomas, the expression of TTF-1 mRNA varied among tumors. The tumors that were composed mainly of small follicles exhibited stronger expression of TTF-1 mRNA than the tumors that were composed of large follicles (Fig. 2C). In all but two cases of papillary carcinoma, the expression of TTF-1 mRNA in tumor cells was identified by ISH (Fig. 2D). In one case of undifferentiated carcinomas, isolated tumor cells exhibited expression of TTF-1 mRNA (Fig. 2E).

\section{Reverse Transcription-Polymerase Chain Reaction}

We examined two cell lines of human undifferentiated thyroid carcinoma, TTA-1 and TTA-2. RTPCR analysis revealed a band of 149 bp corresponding to exon 1 and exon 2 of the TTF-1 gene after 30 cycles in the TTA-1 and TTA-2 specimens (Fig. 3).

\section{DISCUSSION}

The present study was undertaken to examine the expression and localization of TTF-1 in normal, hyperplastic, and neoplastic thyroid tissues using IHC and nonisotopic ISH. In normal thyroids, the expression intensity of TTF-1 mRNA in follicular cells varied among thyroid follicles, whereas TTF-1 protein distributed in almost all nuclei of follicular cells. This heterogeneous expression of TTF-1 mRNA among normal thyroid follicles may indicate the presence of an autoregulation mechanism for thyroid-specific gene transcription. Recently, we hypothesized that TG-initiated, transcriptional regulation of thyroid-restricted genes is a normal, feedback, compensatory mechanism that limits fol-

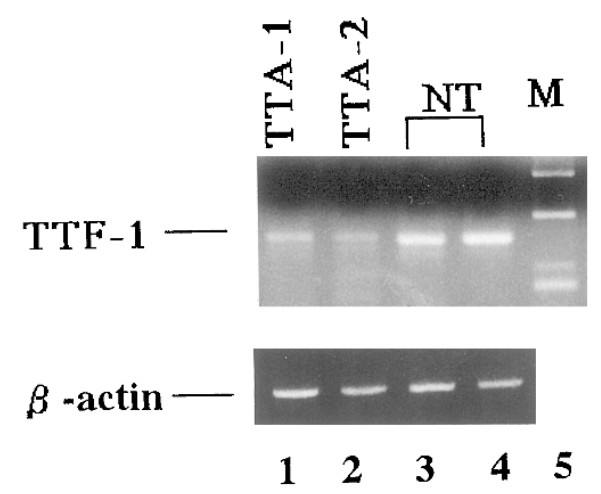

FIGURE 3. Reverse transcription-polymerase chain reaction analysis of TTF-1 mRNA. Undifferentiated carcinoma cell lines TTA-1 and TTA-2 expressing a band of $149 \mathrm{bp}$ corresponding to exon 1 and exon 2 of the TTF-1 gene. NT (lanes 3 and 4), normal thyroid; M, marker. licular function and contributes to follicular heterogeneity (20).

In the present study, IHC and ISH revealed that most differentiated neoplastic tissues, including follicular adenoma, follicular carcinoma, and papillary carcinoma, express TTF-1 protein and mRNA. Staining patterns of TTF-1 were fairly consistent with those of Tg and TPO in normal and hyperplastic thyroid tissues. However, discrepancies in the localization or distribution of TTF-1 and thyroidspecific proteins occasionally were observed, especially in cancerous tissues. This suggests that the activity of TTF-1 might need to be regulated by a variety of mechanisms, such as phosphorylation (21), redox state (22), and interaction with other factors and/or co-activators (23) that could be subjected to regulation themselves and that may be lacking in cancer cells. Therefore, we assume that the presence of TTF-1 alone is not sufficient to produce the differentiated phenotype of thyroid neoplastic cells, although TTF-1 is necessary for full expression of the thyroid-differentiated phenotype.

It has been reported that TTF-1 mRNA is always absent in the undifferentiated (anaplastic) thyroid carcinoma tissues (16) and their cell lines (24). However, in the present study, IHC and ISH revealed the presence of TTF-1 protein and mRNA in one of four specimens of undifferentiated carcinoma. In addition, we examined two cell lines of human undifferentiated thyroid carcinoma, TTA-1 and TTA-2 (19), and demonstrated the presence of TTF-1 mRNA expression after 30 cycles of RT-PCR. These findings suggest that undifferentiated carcinoma cells express TTF-1 mRNA but at very low levels that may not be detectable by Northern blotting. Recently, it was reported that transfection of TTF-1 expression vectors in undifferentiated Fisher rat thyroid cells results in activation of thyroglobulin gene expression (25). Thus, it is conceivable that the loss of the thyroid-specific expression of Tg and TPO in undifferentiated carcinoma tissue may be related to the reduced expression of TTF-1. However, further investigations are required to clarify this matter.

In conclusion, most thyroid tumors express TTF-1 in connection with their functional ability. Therefore, the investigation of TTF-1 provides useful information on the biologic nature of thyroid tumors.

\footnotetext{
Acknowledgments: We thank Dr. Akira Yoshida (Department of Surgery, Kanagawa Cancer Center) for donating the cell lines TTA-1 and TTA-2, and Mrs. Miyuki Ito for skillful technical assistance.
} 


\section{REFERENCES}

1. Damante G, Di Lauro R. Thyroid-specific gene expression. Biochim Biophys Acta 1994;1218:255-66.

2. Dai G, Levy O, Carrasco N. Cloning and characterization of the thyroid iodine transporter. Nature 1996;379:458-60.

3. Civitareale D, Lonigro R, Sinclear AJ, Di Lauro R. A thyroidspecific nuclear protein essential for the tissue-specific expression of the thyroglobulin promoter. EMBO J 1989;8: 2537-42.

4. Guazzi S, Price M, De Felice M, Damante G, Mattei M-G, Di Lauro R. Thyroid nuclear factor 1 (TTF-1) contains a homeodomain and displays a novel DNA binding specificity. EMBO J 1990;9:3631-9.

5. Zannini M, Francis-Lang H, Plachov D, Di Lauro R. Pax 8, a paired domain-containing protein, binds to a sequence overlapping the recognition site of a homeodomain and activates transcription from two thyroid-specific promoters. Mol Cell Biol 1992;12:4230-41.

6. Francis-Lang H, Price M, Polycarpou-Schwarz M, Di Lauro R. Cell-type-specific expression of the rat thyroperoxidase promoter indicates common mechanisms for thyroidspecific gene expression. Mol Cell Biol 1992;12:576-88.

7. Civitareale D, Castelli MP, Falasca P, Saiardi A. Thyroid transcription factor 1 activates the promoter of the thyrotropic receptor gene. Mol Endocrinol 1993;7:1589-95.

8. Shimura H, Okajima F, Ikuyama S, Shimura Y, Kimura S, Saji $\mathrm{M}$, et al. Thyroid-specific expression and cyclic adenosine $3^{\prime}, 5^{\prime}$-monophosphate autoregulation of the thyrotropin receptor gene involves thyroid transcription factor-1. Mol Endocrinol 1994;8:1049-69.

9. Gehhing WJ. Homeo boxes in the study of development. Science 1987;236:1245-52.

10. Lazzaro D, Price M, De Felice, Di Lauro R. The transcription factor TTF-1 is expressed at the onset of thyroid and lung morphogenesis and in restricted regions of the foetal brain. Development 1991;113:1093-104.

11. Yan C, Sever Z, Whitsett JA. Upstream enhancer activity in the human surfactant protein B gene is mediated by thyroid transcription factor 1. J Biol Chem 1995;270:24852-7.

12. Kelly SE, Bachurski CJ, Burhans MS, Glassor SW. Transcription of the lung-specific surfactant protein $C$ gene is mediated by thyroid transcription factor 1 . J Biol Chem 1996;27: 6881-8.

13. Suzuki K, Kobayashi Y, Katoh R, Kohn LD, Kawaoi A. Identification of thyroid transcription factor- 1 in $\mathrm{C}$ cells and parathyroid cells. Endocrinology 1998;139:3014-7.

14. Suzuki K, Lavaroni S, Mori A, Okajima F, Kimura S, Katoh R, et al. Thyroid transcription factor-1 is calcium-modulated and coordinately regulates genes involved in calcium homeostasis in C cells. Mol Cell Biol 1998;18:7410-22.

15. Kikkawa F, Gonzalez FJ, Kimura S. Characterization of a thyroid-specific enhancer located 5?5 kilobase pairs upstream of the human thyroperoxidase gene. Mol Cell Biol 1990;10:6216-24.

16. Fabbro D, Di Loreto C, Beltrami CA, Belfiore A, Di Lauro R, Damante G. Expression of thyroid-specific transcription factors TTF-1 and Pax-8 in human thyroid neoplasms. Cancer Res 1994;54:4744-9.

17. Nakane PK, Kawaoi A. Peroxidase-labeled antibody: a new method of conjugation. J Histochem Cytochem 1974;22: 1084-91.

18. Nomura S, Hirota S, Morii E, Ito A, Kitamura Y. Methods for detecting expression of c-Kit receptor tyrosine kinase and ligand in adult mouse and rat brain. Neuroprotocols 1992;1: 256-62.

19. Yoshida A, Asaga T, Masuzawa C, Kawahara S. Production of cytokines by thyroid carcinoma cell lines. J Surg Oncol 1994; 55:104-7.

20. Suzuki K, Lavaroni S, Mori A, Ohta M, Saito J, Pietrarelli M, et al. Autoregulation of thyroid-specific gene transcription by thyroglobulin. Proc Natl Acad Sci U S A 1998;95:8251-6.

21. Zannini M, Acebron A, De Felice M, Arnone MI, MartinPerez J, Santisteban P, et al. Mapping and functional role of phosphorylation sites in the thyroid transcription factor 1 (TTF-1). J Biol Chem 1996;271:2249-54.

22. Arnone MI, Zannini M, Di Lauro R. The DNA binding activity and the dimerization ability of the thyroid transcription factor 1 are redox regulated. J Biol Chem 1995;270:12048-55.

23. De Felice M, Damante G, Zannini M, Francis-Lang H, Di Lauro R. Redundant domains contribute to the transcriptional activity of the thyroid transcription factor 1 . J Biol Chem 1995;270:26649-56.

24. Heldin NE, Westermark B. The molecular biology of the human anaplastic thyroid carcinoma cell. Thyroidology 1991;3:127-31.

25. Mascia A, De Felice M, Lipardi C, Raffaele G, Cali G, Zannini M, et al. Transcription of TTF-1 gene induces thyroglobulin gene expression in undifferentiated FRT cells. Biochim Biophys Acta 1997;1354:171-81. 